\title{
The effect of word abstractness and pleasantness on pupil size during an imagery task'
}

ALLAN PAIVIO AND HERB M. SIMPSON

UNIVERSITY OF WESTERN ONTARIO

Findings from two studies demonstrate that a $S^{\text {'s }} s$ pupils dilate when he attempts to generate mental images to words. Dilation, which may reflect the cognitive difficulty of the imagery task, was greater to abstract than to concrete words, but did not vary with word pleasantness-unpleasantness.

It is generally recognized that psychological factors are potent determinants of pupil size (Berrien \& Huntington, 1943; Lowenstein \& Loewenfeld, 1962; Sokolov, 1963). Hess and his co-workers found, specifically, that pupillary reactions are affected by the interest value of visual stimuli (Hess \& Polt, 1960; Hess, Seltzer, \& Shlien, 1965), difficulty of mental arithmetic problems (Hess \& Polt, 1964), and pleasantness of stimuli (Hess, 1965). The present study investigated changes in pupil size when $S$ attempts to generate "mental images" of objects or events suggested by stimulus words that vary in concreteness and pleasantness. Previous related research has indicated that concrete nouns elicit images more readily than do abstract nouns, presumably because of the more frequent association of concrete nouns with objective referents (e.g., Paivio, 1965; Paivio, in press). In view of the sensitivity of the pupillary reaction to cognitive activity, it was reasoned that the apparent difference in the imageevoking capacity of concrete and abstract terms should be reflected in differential pupillary reactions to the two classes of words. Hess's report that unpleasant stimuli evoked pupillary contriction whereas pleasant stimuli resulted in dilation suggested further that the pleasantness-unpleasantness of the words might have an effect.

Method

The stimuli were 12 nouns, six of which are relatively concrete and six abstract, as rated by the Es. The concrete nouns exceed the abstract in their capacity to evoke imagery, according to ratings obtained from 32 university students following Paivio's (1965) procedure, and half of each class are relatively pleasant and half unpleasant in meaning as judged by the same Ss using a 7-point pleasant-unpleasant scale. The concrete words were candy, honeycomb, pudding, blister, lice, mucous; the abstract words were charm, love, warmth, agony, disease, sadness.

In general, the procedure was to present each word visually to $S$, who was asked to imagine an object or event related to the word and to press a key when an image occurred. The words, on 35- $\mathrm{mm}$ negative slides, were projected on a ground glass screen at the back of a box-like compartment. $\mathrm{S}$ was seated at the front of the compartment, his head positioned in a head holder to standardize the distance between his eye and the screen at $60 \mathrm{~cm}$. A motor-driven Bolex 16 mm movie camera was used to photograph S's right eye at a rate of 2 frames per sec. through an opening just below the screen. The camera was enclosed in a partially soundinsulated casing to reduce the sound of the camera shutter, and masking was also provided by continuous white noise fed through earphones. An interval timer controlled the inter-stimulus intervals and stimulus durations, and started a clock which recorded the key press used to indicate image arousal. A small light in the base of the lens of the camera went on during the inter-stimulus interval to identify the intervals by overexposing that portion of the movie film. Illumination during projection, provided by the projector and a $30-\mathrm{cm}$ fluorescent tube, was such that pupil size (as assessed using pilot Ss) was "moderate" on the average, allowing for either dilation or constriction to occur. Eastman Kodak Tri-X reversal movie film (165 ASA) was used. To determine pupil size, the film was examined frame by frame using a $10 \times 15-\mathrm{cm}$ film editor, and the diameter of the pupil thus magnified was measured with a millimeter ruler.

Experiment $I$ involved 14 adult Ss $(8$ males and 6 females) who were presented the words one at a time, following exposure to four practice words. Two different, random orders of presentation were used. The exposure duration to each word was $10 \mathrm{sec}$., resulting in 20 photographic frames per word. Six Ss in a control group were exposed to four blank slides equated in brightness with the word slides. Experiment II, involving 20 adult Ss (8 males and 12 females), employed essentially the same procedure with one major change: each word slide was preceded by a 10 sec. presentation of a blank slide of equal brightness, so that an appropriate within-S control was available for each word.

Results

In both experiments, pupil size was averaged over all words of a type (e.g., concrete-pleasant) as well as for the respective control conditions. The effects of pleasantness-unpleasantness were nonsignificant in both experiments (the crucial Fs from the analyses of variance were less than 1.00), and Fig.1 (A \& B) shows the function over time, i.e., photographic frames, only for concrete and abstract words and the control conditions. Average pupil size differed somewhat in the two experiments because a lower level of illumination was used in the second. Otherwise, the pattern of results was highly similar in both. The figure shows an initial 


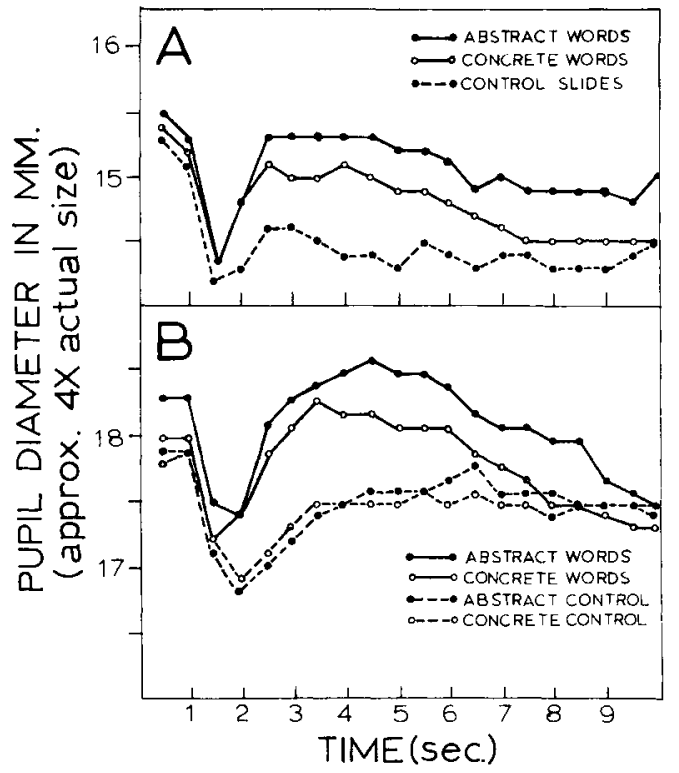

Fig. 1. Mean pupil size in two experiments for Ss viewing abstract and concrete words under imagery instructions, and when viewing blank control slides; Experiment I (A) involved a separate control group, Experiment II (B) involved within-S control conditions.

pupillary constriction (the light reflex) to the presentation of a slide. The reaction to words is dilation followed by gradual reconstriction, and the dilation is apparently greater to abstract than to concrete words. The curves for control conditions are flatter than those for words. These data were evaluated by analyses of variance for repeated measures.

Experiment I. The data from the 20 frames for the experimental group were collapsed into four equal time blocks, and analyzed with pleasantness, concreteness, and blocks as factors. Since the six control Ss were not part of the factorial design, their data were excluded from the analysis. The results showed that the blocks effect was significant $(F=5.18, \mathrm{df}=3 / 39, \mathrm{p}<$ $.001)$, and that the concrete-abstract difference approached significance $(F=4.24, \mathrm{df}=1 / 13, \mathrm{p}<.10)$.

Experiment II. The data were again collapsed into four equal time blocks, and analyzed with stimulus conditions (words vs, blank slides), concreteness, pleasantness, and blocks as variables. The resulting main effects indicate a significant change over time blocks $(F=10.26, \mathrm{df}=3 / 57, \mathrm{p}<.001)$, and that dilation was greater to words than to control slides $(F=47.11$, $\mathrm{df}=1 / 19, \mathrm{p}<.001$ ). The interaction of stimulus conditions by blocks $(\mathrm{F}=10.30, \mathrm{df}=3 / 57, \mathrm{p}<.001)$ indicated that the curves differed for words and control stimuli over time. Since the design included a within-S control condition, any effect of a word attribute would appear only as an interaction of that attribute and word vs. no word conditions. The interaction of stimulus conditions by concreteness was significant $(F=4.98, \mathrm{df}=1 / 19$, $\mathrm{p}<.05$ ), indicating that dilation was greater to abstract than to concrete words.

\section{Discussion}

The similarity in the results of the two experiments (Fig. 1A \& B) and the statistical analysis of the second reliably demonstrate that a S's pupils dilate when he attempts to generate mental images to stimulus words, and that the dilation is greater to abstract than to concrete words. This is not to say that the effect is necessarily due to a central neural process related specifically to imagery. Instead, it can be explained more parsimoniously as a general arousal effect, occurring when the task is cognitively more difficult (cf., Hess \& Polt, 1964). So interpreted, the present findings provide physiological support for rating scale and reaction time data (e.g., Paivio, in press), which also have indicated that it is more difficult to generate images to abstract than to concrete words.

The failure to find a pleasant-unpleasant effect differs from Hess's findings for nonverbal visual stimuli. In addition to the difference in stimuli, however, the tasks used in the studies are different and it is possible that the imagery task may have inhibited any constriction that might have otherwise occurred to the unpleasant words.

\section{References}

Berrien, F. K., \& Huntington, G. H. An exploratory study of pupillary responses during deception. J. exp. Psychol., 1943, 32, 443-449.

Hess, E. H. Attitude and pupil size. Scient. American, 1965, 212, 46-54.

Hess, E. H., \& Polt, J. M. Pupil size as related to interest value of visual stimuli. Science, 1960, 132, 349-350.

Hess, E. H., \& Polt, J. M. Pupil size in relation to mental activity during simple problem solving. Science, 1964, 143, 1190-1192.

Hess, E. H., Seltzer, A. L., \& Shlien, J. M. Pupil response of hetero- and homosexual males to pictures of men and women: a pilot study. J. abnorm. Psychol., 1965, 70, 165-168.

Lowenstein, o., \& Loewenfeld, I. E. The pupil. In H. Davson (Ed.), The eye. Vol. III. New York: Academic Press, 1962. Pp. 231-267.

Paivio, A. Abstractness, imagery, and meaningfulness in pairedassociate learning. J. verbal Learn. verbal Behav., 1965, 4, 32-38.

Paivio, A. Latency of verbal associations and imagery to noun stimuli as a function of abstractness and generality. Canad. J. Psychol., in press.

Sokolov, E. N. Perception and the conditioned reflex. New York: Macmillan, 1963.

\section{Note}

1. This research was partially supported by grants from the National Research Council of Canada (Grant APA-87) and the University of Western Ontario Research Fund. 